Fecha de recepción: julio 2012

Fecha de aceptación: febrero 2013

Versión final: marzo 2014

\section{Diseñar a partir de la identidad. Entre el molde y el espejo}

Marcia Veneziani *

\begin{abstract}
Resumen: El presente artículo muestra a través de un caso -el de la diseñadora argentina Deby Szmuch- un modo de entender la moda desde la "alta costura individualizada". La identidad personal constituye el eje a partir del que se realiza indumentaria. Un modo bien argentino donde se mezclan las historias de los inmigrantes, las propias historias y la inspiración artística en un entramado complejo entre la biografía y el diseño.
\end{abstract}

Palabras clave: alta costura - Argentina - diseño - historia - identidad - inmigración Latinoa-mérica.

[Resúmenes en inglés y portugués en la página 88]

${ }^{(*)}$ Doctora en Ciencias de la Comunicación Social y Licenciada en Publicidad de la Universidad del Salvador. Docente Titular de la Universidad de Palermo en el Departamento de Investigación y Producción de la Facultad de Diseño y Comunicación.

\title{
Introducción
}

Es sabido que los ideales de belleza dependen tanto de la época, como de los contextos en que las distintas sociedades se desenvuelven.

En la antigua Grecia, la idea de belleza concordaba con la verdad ya que se pensaba que la verdad era la que producía la belleza; en cambio para los románticos era la belleza la que promovía a la verdad. “...los románticos piensan en una belleza que produce una mayor verdad y realidad” (Eco, 2007, p. 317).

En otros tiempos, la opulencia física era sinónimo de belleza. Basta observar la pintura de las “Tres Gracias” de Rubens expuesto en el Museo del Prado, en Madrid.

También lo que hoy llamamos obesidad o corpulencia fue sinónimo de bienestar y de status. La figura femenina de fines del Siglo XIX da cuenta de ello. Alcanza con recorrer los escritos de Thorstein Veblen (1898) para reconocer la corpulencia femenina, ya en su físico ya en su vestimenta (la figura en S, el corsé afinando la cintura, para mostrar un pecho abundante).

La indumentaria debía responder a una función social (ociosidad) y al mismo tiempo mostrar la opulencia económica del esposo y su linaje.

¿Cuál es la belleza que hoy refleja la moda? Sin duda un cuerpo delgado es considerado es- 
tético. La moda hoy impone estereotipos a través de los medios de comunicación. Mucho de ese encantamiento la producen las técnicas del photoshop y del diseño: "los magos de la moda consiguen actualmente ocultar con habilidad las figuras de una corpulencia media o, con el efecto de sus vestidos, hacer que señoras que no estén del todo en el peso ideal, parezcan modelos" (Scquicciarino, 1990, p. 125).

La moda se podría comparar con una tirana a la que se está obligado a responder a todos sus antojos. El mercado y las tendencias son las que marcan su ritmo frenético y acelerado. Sin embargo, hay diseñadores que están trabajando -en una suerte de rescate de la propia identidad de sus clientas- en líneas que escapan a los cánones impuestos por ella. Es decir, más allá de las tendencias.

Piensan un poco como los griegos, en que la belleza debe pactar con la verdad y otro poco como los románticos: que la belleza los debe conducir a la verdad.

En la Argentina, luego de la crisis del 2001, surgieron algunos diseñadores capaces de soñar sus propias creaciones y además con la necesidad de contar historias: propias y ajenas. En un país de inmigrantes, hay cientos de ellas.

Este artículo trata, de una de esas tantas historias.

Y así como están aquellos que relatan cuentos, están otros que lo hacen desde el propio oficio, el que aquí nos convoca es el de la moda.

Cuentan historias de amor y de guerra, de pasados turbulentos, de mujeres que viven en un país siempre en crisis, de maternidades y fiestas, de alegría, de razas y lugares y por qué no, de generaciones de inmigrantes. Habla de un país y de un continente. En definitiva, habla de quienes habitan la Argentina.

\section{Deby Szmuch. Modelando desde la identidad}

Deby Szmuch aprendió a los 10 años de la mano de una modista -bien criolla- de alta costura en el barrio porteño de Caballito, donde transcurrió su infancia, y a los 12 diseñó su primer vestido de novia.

Su bisabuela ucraniana (sobreviviente del Holocausto) hacía vestidos de novias para Harrod `s cuando se instaló en Buenos Aires. Pero nadie más de su familia se dedicó a la alta costura. Sonríe y dice que fue algo que "ella lo trajo" en sus genes.

Szmuch trabaja desde la moldería: a partir de un plano genera tres. Para ella, comenzar de una y llegar a tres dimensiones es algo casi mágico. Es que diseña directamente sobre el cuerpo.

Los conceptos con los que trabaja son los mismos cuerpos de sus clientas y sus historias, sus gustos, sus miedos y sus sueños. Trabaja moldeando como un artesano la cerámica: desde lo que le molesta y lo que no le molesta a la persona. Lo primero que le pregunta a sus clientas es lo que no quieren. Es decir desde el "no" juntas hacen que sea un "sí". Ella toma el defecto como una virtud. Da vuelta el desperfecto corporal y lo transforma en un atributo. Diseña desde la percepción que la propia persona tiene de su imagen aunque no sea lo que se vea en la realidad. Como una suerte de adivina, Szmuch entra en la cabeza de sus clientas. 
Si Kenzo diseña sobre la tela, ella lo hace sobre el cuerpo.

Compra la tela con sus clientas porque la diseñadora confiesa que con mucha frecuencia, la idea que tienen ellas en la cabeza no es la misma que tendrán cuando se observen frente al espejo, envueltas en la tela deseada. Éste les devuelve una imagen que no es la que imaginaban: ya sea por el color o por la textura.

Juntas, recurren a escuchar a lo que el propio cuerpo y el espejo tienen para decirles.

Szmuch explica porqué el color, aunque guste, puede quedar mal. Y eso tiene que ver con la proyección que cada persona tiene de sí misma. Quizás terminen llevando otro que jamás hubiesen pensado: en vez de violeta, un amarillo.

La moldería comienza sobre el cuerpo. En vez de hacerlo con papel, ella toma una tela cualquiera, que a partir de ese momento será el molde.

Emprende la tarea desde del cuerpo desnudo, sin nada que engañe la vista y a partir de allí, recién puede comenzar a pensar el diseño.

Parte de la identidad de la persona: con lo que las mujeres le cuentan.

Szmuch las interroga, indaga, pregunta como un detective.

Una vez que el cuerpo y el espejo "aprueban”, recién se comienza con la tela. La diseñadora tiene que saber como funciona "ese cuerpo", conocer sus secretos y vericuetos, las sombras y las luces.

Cuenta -a modo de ejemplo- que una de sus clientas ama el continente Africano. Cuando diseña para ella, en vez de pensar en su nombre piensa en África. Porque sabe que a ella es algo que la conmueve, que la supera, que no lo puede manejar. Por lo tanto diseña a partir de ese lugar. Mira fijo y dice: “-No pensás en un rosa o un celeste si pensás en África”. Y comienza la investigación: tribus, colores marrones, verdes, rojos....

Otras buscan algo femenino y Szmuch piensa en los años 50 y en Hollywood.

La inspiran Elizabeth Taylor y Marilyn Monroe. Ve películas de la época y las plasma en los volados, en el movimiento, en las telas que escoge.

Cuando piensa en Latinoamérica lo relaciona con lo pasional: se inspira en las pinturas de Frida y en las novelas de Isabel Allende.

Distingue lo "criollo" de lo Latinoamericano y lo amalgama: Frida sobre la tela y el charol en los pies. Los libros de Allende también le sirven para contar "desde las vísceras". Lo que hacen los vestidos de Szmuch inspirados en la novelista chilena es contar historias a partir de los colores: marrones, rojos, algún azul. Dice que no usaría pasteles, ni rayados quizás sí algunas flores y algún búlgaro.

Todo lo que ve y piensa para sus diseños es en imágenes: si la inspiración viene de las novelas de Florencia Bonelli que es más romántica, los materializa en puntillas, encajes y transparencias.

Cuenta que otra de sus clientas es abogada pero que su pasión son las danzas modernas contemporáneas. Para un vestido de fiesta que le encargó, se inspiró en Isadora Duncan. Con el físico de su clienta y la Duncan en la cabeza le diseñó el vestido. Porque Szmuch conocía (a partir de sus larguísimas charlas con la abogada) que el baile era tan importante para ella como el Derecho.

Si tiene que pensar un concepto para la mujer criolla imagina a Berni: la mezcla de texturas y colores. Porque los argentinos, sostiene, somos una mezcla de razas y nacionalidades. Y por supuesto, marca la cintura (una necesidad típicamente latina). 
Cuenta que hay clientas que son bien latinas y quieren parecer hindúes. Pero el espejo delata: si una mujer es opulenta y quiere ser lánguida no lo podrá hacer a través de un vestido, pero sí a través de la vida. Confiesa que no puede hacer algo que se oponga a lo que el otro es.

Szmuch trabaja con el alma de la persona. Admite que el gran desafío es darle a una mujer eso que le falta: por ejemplo un pecho que ya no está. Así, esa noche, la mujer triste que dice "para qué si ya no los tengo o tengo uno solo", por medio de breteles y juegos de diseño vuelva a sentir que tiene un cuerpo pleno. Y entonces sí: el milagro ocurre.

Como una maga, la diseñadora crea una empatía con su clienta, provocando la complicidad necesaria para sentir esa conexión y sentir ella misma lo que es estar en la piel del otro. Se establece una relación muy personal entre ambas. Durante el proceso creativo de la prenda, ve el cuerpo de sus clientas por los menos seis ó siete veces. Por lo tanto, una cierta complicidad es inevitable: comparten secretos y sueños. Recuerdan a novelas criollas, específicamente la parte en que, durante las primeras horas de las tardes de cálidos veranos de campo, los demás duermen la siesta mientras las mujeres cuchichean.

Szmuch cuenta de mujeres a las que les molesta su gran bajo vientre, consecuencia de varios embarazos. De ellos ella hace lo que llama una "fiesta" a la maternidad y que esa noche no "moleste".

La diseñadora hace desaparecer "partes" de acuerdo a la tela. O, por el contrario, hace que se vean otras, que resalten lo suficiente para que otras se oculten. Se compara con un arquitecto y dice: "para que no se vean las cañerías tiene que haber paredes. Con el cuerpo y las telas es lo mismo". Trabaja con todas las texturas. La elección depende de la clienta, del modelo, de lo que quiere gastar, de lo que sabe de la persona. Algunas personas -dice- son definitivamente gasa; otras, seda; otras, tul; otras bordados; o terciopelo, o chifón. Cada sujeto es una textura distinta, como su identidad.

Si no hay conexión con la persona, Szmuch no puede trabajar. A sus diseños los define como "bohemios libres, sin cartón. Su función es la de "desacartonar". Si en su atelier una mujer busca algo estructurado no lo va a encontrar.

Ella hace lo que ellas "son”. -No un "Deby Szmuch", dice-“pero sí, yo como diseñadora, hago lo que les va a quedar bien".

\section{De lugares y de historias}

...Tú como yo, viajero, en un día cualquiera

Llegamos al camino sin elegir la acera.

Nos pusimos un traje como el que llevan todos

$\mathrm{Y}$ adquirimos su aspecto, sus costumbres, sus modos

Alfonsina Storni [1918] (1995, p.70)

Deby Szmuch en la actualidad trabaja ocasionalmente para extranjeros. Pero en general lo hace para un público nacional. De todos modos, sus vestidos de novia cruzan fronteras: Ucrania, México y Ecuador. Todas argentinas que se casaron allá y acá: el mismo vestido para dos países y estaciones. 
Los amigos dicen que ella tiene un estilo bien europeo y no tan latino. Lo descubrió porque en sus inicios (durante la crisis del 2001) quienes compraban sus colecciones cuando estaba en la Feria de Palermo eran casi todos turistas europeos.

Afirma que durante esos años no lograba que su gusto entrase en el mercado local. En cambio, cuando trabajó un tiempo en España, podía hacer cualquier cosa y se lo compraban. Algo pasaba. Más tarde descubrió que hay cosas que se muestran en la Argentina más tarde que en Europa. Habla de un desfasaje: la mujer argentina se está animando de a poco ahora a mostrar su propia imagen y no la que está impuesta.

Considera que la mujer europea no necesita tanto marcar la cintura, la latina sí. La primera usa un vestido más cómodo. A la latina le gusta marcar más las curvas, la cintura, el busto, el cuerpo.

A su vez, diseñar para la mujer de la ciudad de Buenos Aires es distinto que para la del interior del país, ya que esta última es más tradicionalista porque está mucho más expuesta que en la gran ciudad.

Admite que diseñar para la mujer de Buenos Aires le da más libertad, puede hacer lo que se le ocurra. Hay más posibilidades de variación. La porteña quiere que la vean, -“¡Imaginate!, dice- "si son millones, necesitás que te vean, en el interior, especialmente en los pueblos es mejor que "no te vean". Y eso está dado por los prejuicios, por "el que dirán". Marca diferencias a la hora de diseñar: la americana es más práctica que la europea y que la latina.

Para ella, sus colecciones son bien cosmopolitas. No diseña con límites.

Diseña desde y para cada una de sus numerosísimas clientas a quienes conoce a la perfección, por lo tanto, jamás podría hacerlo en serie ya que cada persona -afirma- es única.

Su secreto es trabajar con la identidad de la persona, su cuerpo y su historia.

Cuenta que a ella la marcó la memoria. Detalla con minuciosidad el vestido de novia que diseñó para sí misma: lo realizó con retazos de tela de cada una de los vestidos con que se casaron las mujeres de su familia: su madre, su abuela su bisabuela, amigas y madres y abuelas de sus amigas, también de clientas que habían sido importantes para ella.

Sucede que, el vestido nupcial de Szmuch narra su historia familiar. Y este concepto es significativo para la diseñadora ya que ella -sostiene- es el resultado de una historia.

Fue un homenaje a su abuela y a la bisabuela inmigrante que era modista de alta costura y que "le pasó el oficio sin conocerla" (sic). Y que hasta llegó a trabajar con su máquina de coser. Para ella fue como construir la propia identidad. Será por eso que trabaja para mujeres que les interesa reconstruir su vida.

Utiliza el color para que se note más la identidad ya que éstos hablan de su historia y de su interior.

Trabaja con todas las paletas de color, pero prefiere el champagne y el natural, el beige y el tostado. Ama los colores del pasado, de lo antiguo.

A lo suyo lo llama "alta costura, individualizada".

Deby Szmuch tiene la necesidad de dibujar todo el día, de mostrar lo que siente, de sacar las historias afuera. Quizás esto de marcar la identidad y contar la historia de la gente venga de recuperar algo que tiene que ver con su pasado. Cuenta en voz baja que empezó hace años estampando remeras con fotos de su familia. Ríe: "debe andar alguien por ahí dando vueltas con la cara de mi abuela". 


\title{
Entre el espejo y el alma
}

\author{
....Ya es bastante que ahora quieras \\ Escuchar mi fantástica historia. \\ Una historia iniciada en otros días, \\ cuando ardían los soles del verano... \\ una canción simple que servía para marcar \\ el ritmo de nuestros remos... \\ Cuyos ecos viven aún en la memoria, \\ Aunque los años envidiosos inviten al olvido...
}

Lewis Carroll [1871] (1976, p. 155)

Como se ha mencionado al inicio de este artículo, la moda refleja el espíritu de la época, y de ello dan cuenta variados estudiosos que han tratado el argumento que nos ocupa, a lo largo de la historia.

Por lo tanto, los diseñadores del mundo de la moda no deben perderlo de vista al lanzar una nueva colección para que sus creaciones "encajen" y puedan ser aceptadas por un público cada vez más sediento de novedades y que además se ajusten a los mandatos de los estereotipos de belleza de la actualidad.

Estamos en la era del personalismo, donde cada uno pareciera tener la necesidad imperiosa de expresarse y manifestar sus opiniones y no necesariamente calificadas (cuenta de ello lo dan los medios de comunicación que han surgido de la mano de las nuevas tecnologías) Todos son periodistas, escritores y poetas. Declaran a los cuatro vientos su versión de los hechos, quien quiera puede contar su historia. Nada impide (salvo la propia ética personal cuando se tratan temas delicados) que se dictamine a piacere la exégesis de los acontecimientos.

¿Por qué escuchar sumisos si se puede contar la propia versión? ¿Por qué no aprovechar la oleada? ¿Por qué no mostrarse de una vez por todas y que todos sepan que uno existe? ¿O acaso si uno no lo hace está fuera de moda?

Estas preguntas resultan ineludibles si se aborda el tema de la identidad y la necesidad de exhibirla de modo elocuente y que se observa de modo creciente en los últimos años. Por lo tanto, su manifestación a través de la moda es inevitable, porque es ésta última la que asegura ante el mundo exterior visibilidad y existencia.

¿Quién soy? ¿Cómo soy? ¿Cuál es mi historia? Parecerían ser, por ende, los ejes centrales que atraviesan el relato de nuestra contemporaneidad.

No es simple para los diseñadores encarar semejante empresa sin contar con la empatía suficiente para ponerse en el lugar del otro y mostrarlo como si fuese un retrato. El desafío es grande: en lugar de una fotografía que es más evidente, se debe plasmar en un traje de moda. Y la moda hoy, además de seguir las tendencias, requiere mostrar la identidad del portador, su propio retrato. 
No se puede ya desconocer que otras ramas del saber tienen necesariamente una implicancia decisiva en el análisis de la cuestión. Ya Flügel (1964) en sus estudios sobre la psicología de la moda se ocupó hondamente de los aspectos profundos de la vestimenta que se relacionan, entre otras, con las funciones de pudor, del exhibicionismo y de la ornamentación. El autor lo expresaba de modo contundente al afirmar que:

La circunstancia de que la ropa pueda cumplir eficazmente esta doble y en el fondo contradictoria función, se relacionan con el hecho (al que ya hemos aludido) de que las tendencias de exhibición y de vergüenza se vinculan en su origen no con el cuerpo vestido sino con el cuerpo desnudo. La vestimenta sirve para cubrir el cuerpo y gratificar así el impulso de pudor. Pero al mismo tiempo puede realzar su belleza, y esta fue probablemente su función más primitiva... (Flügel, 1964, p. 19).

Hoy más que nunca en el campo del diseño de indumentaria se impone el hecho de ir "más allá de las formas" y de alargar las áreas de estudio de la moda.

La interdisciplinariedad se presenta entonces como ruta obligada a emprender para aquellos que otrora eran sólo maestros de la aguja y del dedal. La psicología, la historia, la arquitectura, la sociología, la comunicación, resultan saberes fundamentales para quienes deseen recorrer exitosamente los senderos del diseño de indumentaria.

¿Cómo contar la historia de alguien sin comprender su contexto? ¿Cómo diseñar un estilo gótico sin conocer la historia de la Edad Media, sin verla plasmada en sus edificios y catedrales, en los trajes que la evidenciaban en sus formas, colores y texturas?

¿Cómo comprender el amor por las danzas o por la pintura de los manieristas si jamás se ha tenido un acercamiento teórico al arte pictórico? ¿Cómo leer la cultura de un pueblo si no se conoce su historia? ¿Cómo construir (a modo de un arquitecto) un indumento que refleje la identidad del cliente desconociendo los principios básicos de la psicología? Afirmaciones como la de Hermann Lotze (1897) acerca de que la vestimenta al amplificar el volumen ilusorio del propio cuerpo otorgaría la sensación de tener mayor poder y por lo tanto nuestro "yo corporal" se extendería ocupando de este modo mayor espacio. Este y tantos otros, son algunos de los conceptos que Flügel (1964) retoma en sus estudios sobre el análisis del vestido y que son sólo un ejemplo de la importancia del abordaje del tema desde otras ciencias y autores.

Este último entiende también, que las sensaciones no se refieren sólo al sentido de la vista sino que se extenderían también al tacto. Por lo tanto, si la prenda en cuestión no está acorde con las aspiraciones del portador se convertiría en algo extraño más que la propia y personalísima extensión del "yo". Citando luego a Flaccus decreta: (1906) "la función "extensiva” de las prendas debe ser tal que esté en armonía con nuestros impulsos más que bajo nuestro control directo" (En Flügel , 1969, p. 41).

Así pues, se ha pretendido mostrar un caso de diseño de autor, como el de Deby Szmuch, con el fin de ilustrar el modo en que trabajan hoy los diseñadores que entienden la moda como una expresión más que elocuente de la propia identidad, bien personal y cosmopolita. Una famosa frase de Balzac sirva quizás para ilustrar lo expuesto: “...el atavío es el más elocuente de todos los estilos...forma parte del propio hombre, es el texto de su existencia, su clave jeroglífica" (Honoré de Balzac [1830], 1982, p. 121) 


\section{Referencias Bibliográficas}

De Balzac , H.(1830). Trattato de la vita elegante. Milán: Longanesi, 1982, p. 121.

Eco, U. (2007). Historia de la Belleza (8 Edición). Barcelona: Lumen.

Flaccus, L. W. (1906). Remarks on the Psychology of Clothes, Pedagogical Seminary, vol XIII. Flügel, J. C. (1964). Psicología del vestido. Buenos Aires: Paidós.

Lewis, C. [1871] (1976). Los libros de Alicia (2a Edición). Buenos Aires: Corregidor.

Lotze, H. (1897). Microcosmus, libro V en Flügel, J. C (1964). Psicología del vestido. Buenos Aires: Paidós.

Scquicciarino, N. (1990). El vestido habla: consideraciones psico-sociológicas sobre la indumentaria. Madrid: Cátedra.

Storni, A. (1995). Poesía Selecta: Alfonsina Storni, “Si la muerte quisiera” en El dulce daño. Barcelona: Edicomunicación.

Summary: This paper shows through the case of the argentine designer Deby Szmuch, a way of understanding fashion from the "individualized couture." Personal identity is the axe from which to make clothing. The tipycal argentine way of dressing mix the stories of immigrants, their own stories and artistic inspiration in a complex network between biography and design.

Keywords: Argentina - design - haute couture - history - identity - immigration - Latin America.

Resumo: $\mathrm{O}$ artigo mostra através de um caso -o da designer argentina Deby Szmuch- um modo de entender a moda desde a "alta costura individualizada". A identidade pessoal constitui o eixo a partir do qual se realiza indumentária. Um modo bem argentino onde se misturam as histórias dos imigrantes, as próprias historias e a inspiração numa rede complexa entre a biografia e o design.

Palavras chave: alta-costura - Argentina - design - história - identidade - imigração - Latinoamérica. 